SGientia studia, São Paulo, v. 9, n. 1, p. 129-47, 2011

\title{
st \\ Ética e justiça nas pesquisas sediadas em comunidades: o caso de uma pesquisa ecossistêmica na Amazônia'
}

\author{
Nicolas LeGHopieR
}

\begin{abstract}
茴
RESUMO

A partir dos anos 1970, os métodos de pesquisa participativa sediada em comunidades ganharam pouco a pouco crédito no campo das pesquisas aplicadas, ocasionando mutações epistêmicas e éticas nas práticas de pesquisa com participantes humanos. Este artigo apoia-se sobre um exemplo de pesquisa "ecossistêmica" em saúde ambiental, conduzida em parceria entre pesquisadores universitários (Canadá e Brasil) e habitantes das margens de um rio da Amazônia brasileira, o Tapajós. Esse exemplo ilustra as tensões que afetam o quadro conceitual no qual são habitualmente colocadas as questões de ética da pesquisa com participantes humanos, principalmente os princípios cardeais retirados do relatório Belmont, e muito particularmente aqueles de beneficência e de justiça. Esse gênero de prática científica implica um desdobramento da responsabilidade dos pesquisadores, entre a pesquisa e a ação.
\end{abstract}

PALAVras-Ghave • Ética da pesquisa. Abordagem ecossistêmica. Pesquisa participativa. Dilema ético. Saúde ambiental. Saúde global. Amazônia.

\section{INTRODUÇÃO}

As pesquisas participativas comunitárias (community-based participatory research, daqui em diante designada por PPC) formam uma família de métodos reunidos em torno de práticas e de valores. As PPC constituem um dispositivo de enquete que se baseia na associação entre os pesquisadores e os grupos concernidos (habitantes de uma localidade, trabalhadores de uma empresa, alunos de uma escola, poderes públicos etc.) em torno de um problema de pesquisa que faça sentido para todos os envolvidos. Segundo o caso, chama-se aos grupos concernidos de "comunidades", "sociedade civil" ou "público" (cf. Mohan, 1999). Essas pesquisas são "participativas" uma vez que os gru- 
pos concernidos vão participar no desenvolvimento da pesquisa, no momento do início da operação e da avaliação prática de seus resultados, mas também, complementarmente, no momento de definir os problemas de pesquisa e de formular as hipóteses. Essas pesquisas têm como fim explícito realizar uma integração entre o conhecimento e a ação, tendo em vista o benefício de todos os participantes e não somente o dos pesquisadores (cf. Israel et al., 1998).

Essas estratégias participativas da pesquisa com seres humanos constituem de muitas maneiras uma alternativa com relação aos modelos tradicionais da pesquisa. Em um primeiro momento, após ter sublinhado três características que as distinguem das metodologias tradicionais que privilegiam a posição de distanciamento do pesquisador com relação ao objeto, insistirei no fato de que as PPC produzem tensões sobre o quadro ético predominantemente empregado na reflexão sobre a pesquisa conduzida com seres humanos; quadro ético que se funda em princípios. Em um segundo tempo, apresentarei um estudo de caso que ilustra algumas dessas tensões, mostrando a necessidade de um esclarecimento da esfera de responsabilidade dos pesquisadores.

\section{As PESQUISAS PARTIGIPATIVAS: QUALIDADES E FRAGILIDADES}

\subsection{ESPEGIFICIDADES NO PLANO METODOLÓGIGO}

As PPC apresentam pelo menos três características que fazem sua especificidade. A primeira é que elas abordam os problemas de pesquisa sem reduzir-lhes a complexidade e o caráter multidimensional. As pesquisas sediadas em comunidades são fortemente contextualizadas, e os conhecimentos produzidos são tidos como pertinentes, significativos e localmente apropriados (cf. Green \& Novick, 2001). O envolvimento dos participantes, ao mesmo tempo, supõe e permite compreender como um fenômeno (por exemplo, uma epidemia, uma poluição que tem consequências para a saúde etc.) inscreve-se nas dinâmicas ambientais, econômicas e sociais que o atravessam (cf. Israel et al., 1994).

Uma segunda característica introduz uma ruptura com relação ao modelo clássico de pesquisa científica. Enquanto a visão tradicional da prática científica foi construída em torno de uma dicotomia entre saber e poder, entre a produção de conhecimento e as aplicações, entre as ciências e a política, as PPC possuem frequentemente o objetivo de contribuir para o reforço da capacidade de agir das pessoas concernidas (empoderamento). A emancipação de grupos social e economicamente dominados pode tornar-se um dos fins da pesquisa científica - e não apenas uma "repercussão" ou um 
simples efeito secundário. Os conhecimentos produzidos pelas PPC são nesse sentido explicitamente interessados. Eles devem permitir que as comunidades dominadas reforcem suas capacidades de agir sobre os problemas que as afetam. Sem pretender desenhar aqui a genealogia complexa desse engajamento da pesquisa no terreno político, cabe mencionar pelo menos duas fontes: as pesquisas-ação de Kurt Lewin nos anos 194.O, conduzidas por ele com os trabalhadores em seus meios de trabalho (cf. Lewin, 1946; Adelman, 1993), e as práticas de educação popular elaboradas por Paulo Freire nos anos 1960 e 1970 (cf. Freire, 1978).

Enfim, as PPC aderem a uma exigência de reflexividade. A participação das comunidades não tem um valor simplesmente instrumental, no sentido de que torne mais fácil a coleta dos dados ou a aceitação dos resultados. A participação conduz também a questionar explicitamente a atitude dos que tomam partido, o valor de um problema de pesquisa, a utilidade na prática dos conhecimentos gerados etc. Como insistem muitos autores, um ideal de equidade regula as relações entre os pesquisadores e as comunidades (cf. Minkler et al., 2003), o que implica em ir ao contrapelo de uma dominação de tipo paternalista entre os pesquisadores e os sujeitos (cf. Müller-Mirza, 2009), em particular, nas pesquisas que implicam os "pesquisadores" do norte e os "parceiros" do sul. Sem apagar as diferenças entre esses dois tipos de parceiros, no plano simbólico e no das competências, as PPC poderiam ser o lugar de uma relação mais igualitária e horizontal entre pesquisadores e participantes.

Essas características das PPC têm como consequência a modificação da postura tradicional do pesquisador, posição de contrapeso, que mantém uma distância com relação ao objeto. Ainda que sejam compatíveis com os principais valores epistêmicos próprios a toda pesquisa de conhecimento verificado (adequação empírica, coerência interna etc.), essas formas de pesquisa demarcam-se daquelas que estão centradas no emprego de modelos preditivos, descontextualizados ou reducionistas (cf. Lacey, 2008). Esse distanciamento com relação aos padrões dominantes é reforçado por especificidades procedimentais. Por exemplo, o plano da enquete das PPG não é, com frequência, inteiramente fixado de antemão. Ele pode precisar ser transformado durante o curso da pesquisa, principalmente a partir das interações entre os pesquisadores e as comunidades. Além disso, os dados coletados pelos pesquisadores incluem, tanto quanto possível, os valores dos participantes. No caso das abordagens colaborativas, são os próprios participantes que coletam os dados; o que pode gerar para a pesquisa informações mais ricas e de maior conteúdo significativo, aumentando, entretanto, o risco de vieses difíceis de controlar. Reencontra-se, desse modo, a questão mais geral da pluralidade dos critérios epistêmicos envolvidos e também a questão da clivagem entre as abordagens qualitativas e quantitativas (Strauss \& Corbin, 2008). As comissões 
de financiamento e os pares encarregados de avaliar a qualidade desses projetos devem forjar critérios de avaliação que levem em conta essas especificidades. Isso nem sempre é simples, mesmo se esse tipo de metodologia é cada vez mais aceito, pelo menos na América do Norte (Turckheim et al., 2009).

\subsection{Tensões Relativas ao Quadro da AVALiaÇão Ética}

Abordar a dimensão da avaliação ética das PPC supõe levar em conta vários pontos de vista e não somente a atitude dos pesquisadores com relação aos participantes. Do lado dos participantes, conduzir esse gênero de enquete supõe inevitavelmente um engajamento pessoal importante, pois será necessário consagrar bastante tempo nas reuniões comunitárias, saber negociar em um contexto em que a dimensão política pode mostrar-se repleta de consequências, manifestar um senso de equidade a fim de instaurar e conservar boas relações com os participantes etc. Fala-se a esse respeito de uma "ética da implicação", característica do procedimento dos pesquisadores engajados nesse gênero de pesquisa (Shore, 2006, p. 11). Essa implicação é compreendida também como implicação pessoal, humana e relacional. Do lado das comunidades, as PPC não são anódinas. Enquanto ocasião para os participantes de entrar em interações sociais mais ou menos duráveis com os intervenientes externos, essas pesquisas podem abalar os equilíbrios sociais estabelecidos. Encontra-se aqui a constatação, bem conhecida pelos pesquisadores de ciências sociais, segundo a qual todo processo de pesquisa - sobretudo se é feita por pesquisadores que não são membros da comunidade concernida - introduz, de imediato, perturbações que podem ter repercussões duráveis (cf. Minkler, 2004). Nessas interações, podem ser refeitas relações de dominação simbólica, mesmo quando os pesquisadores expressam sua "boa vontade". A fragilidade e a vulnerabilidade de pessoas concernidas pelo problema que é objeto da pesquisa requerem uma ética do cuidado (care), lúcida sobre as condições contextuais nas quais se desenvolvem as relações (Thiery \& Cerf, 2009).

A adequação entre essa dimensão relacional e os quadros correntes da ética da pesquisa com seres humanos não é evidente. A abordagem tradicional para a avaliação dessa ética foi esclarecida no meio dos anos 1970, nos Estados Unidos, principalmente com o relatório da Comissão Nacional Americana, publicado em $197^{8}$ (American National Commission, 1984 [1978]), o qual trouxe à luz um triplo referencial que deu origem à corrente do principialismo, fazendo referência a três princípios éticos fundamentais: a beneficência, o respeito aos sujeitos e a justiça. Vamos relembrá-los brevemente. O primeiro desses princípios exige que não se causem males aos participantes e à sociedade e, destarte, se promova seu bem-estar. $\mathrm{O}$ segundo exige que se 
respeite a liberdade dos sujeitos e sua capacidade de deliberação. O terceiro princípio exige uma distribuição justa das tarefas e benefícios da pesquisa. Esses três princípios não constituem regras operacionais precisas (cf. Macklin, 1999), mas servem de inspiração a essas regras e, além disso, continuam hoje em dia a servir de base para a maior parte das recomendações feitas aos pesquisadores que conduzem pesquisas com participantes humanos (cf. Massé, 2003).

Nancy Shore conduziu uma rica enquete sobre a pertinência desses princípios, do ponto de vista dos pesquisadores que conduzem PPC. Segundo ela (Shore, 2006), as pesquisas participantes requerem adequações importantes na interpretação prática desses princípios, sem, contudo, invalidá-los enquanto princípios. Em primeiro lugar, nota-se que o princípio da beneficência, à luz das PPC e contrariamente a outras pesquisas clínicas e, sobretudo, epidemiológicas, não pode reduzir-se à simples nãomaleficência: as comunidades participantes devem claramente encontrar um benefício na (e em função da) pesquisa. A abordagem participativa implica, portanto, em deixar claramente um lugar para a avaliação do processo pelos próprios participantes, o que está longe de não levantar dificuldades, sobretudo em contextos multiculturais. Os pesquisadores interrogados por Shore consideram, além disso, que esses resultados não se interpretam somente em termos de indicadores epidemiológicos ou socioeconômicos (incidência da doença, renda média, qualidade de vida etc.) mas também em termos do reforço da capacidade de agir das comunidades participantes.

Em segundo lugar, o princípio de respeito aos sujeitos, nas PPC, aparece menos como uma etapa determinada no processo de pesquisa (por exemplo, o momento da obtenção do "consentimento informado") que como um processo relacional, mantido na duração do projeto, a favor de um clima de confiança mútua. Os pesquisadores insistem assim sobre a autenticidade do participativo: a participação deve ser algo diferente de um simples instrumento que serve para reforçar a aceitação social de uma proposição definida de antemão. Ela deveria permitir que se fizesse de modo que as pessoas contribuíssem efetivamente para refinar a pesquisa e para torná-la mais pertinente. Esse ponto é particularmente delicado, na medida em que o termo "participação", utilizado a propósito de práticas científicas muito heterogêneas, que vão da simples consulta à coconstrução, pode atrapalhar a análise lúcida das relações que se estabelecem precisamente na relação entre os pesquisadores e os participantes.

Em terceiro lugar, a exigência de justiça distributiva formulada no terceiro princípio sofreu um deslocamento significativo. No relatório Belmont, esse princípio era formulado tendo em mente os riscos de exploração pelos pesquisadores de sujeitos vulneráveis ou desconsiderados (experimentum in corpore vili, cf. Chamayou, 2008). De fato, adotando um procedimento participativo e sob a condição de que sejam ho- 
nestamente conduzidas, as PPG não parecem apresentar risco de injustiça distributiva: o fardo da pesquisa e seus benefícios pretendidos estão ligados, em princípio, às mesmas pessoas. Além disso, o posicionamento das PPC em favor da autonomia e do reforço da capacidade de agir dos participantes posiciona esse gênero de pesquisa como um meio para corrigir as injustiças pré-existentes, atacando as desigualdades de condição. Alguns autores tendem assim a reinterpretar o princípio, enunciado no relatório Belmont em termos de "justiça distributiva", no sentido de uma "justiça relacional" (cf. King, Henderson \& Stein, 1999). Veremos, entretanto, a partir do caso exposto com detalhe mais abaixo, que a questão da justiça permanece uma questão delicada nas fronteiras da esfera de responsabilidade dos pesquisadores.

\subsection{O PROBLEMA DA DISTINÇÃo ENTRE PESQUiSA E PRÁTICA}

Se os princípios que estão na base da avaliação ética da pesquisa com seres humanos podem assim encontrar uma interpretação apropriada para as PPC, é preciso notar que esse quadro geral é construído sobre um pressuposto, que Shore não percebe senão de modo incidental, ainda que ele tenha inegavelmente certa importância. A introdução do relatório Belmont propõe, com efeito, distinguir a "pesquisa" da "prática": "É importante distinguir entre a pesquisa biomédica (...) de um lado, e a prática terapêutica corrente de outro, com o fim de conhecer quais são as atividades que necessitam sofrer uma revisão para a proteção dos seres humanos" (American National Commission, 1984 [1978]). Essa distinção prévia entre prática e pesquisa é geralmente tida como estabelecida nas comissões de revisão da pesquisa. A pesquisa distingue-se da prática corrente porque ela constitui uma atividade que visa principalmente produzir conhecimentos. Entretanto, acontece com frequência que se tenha dificuldade para separar o que pertence a um ou ao outro desses gêneros de atividades - em particular, no domínio da saúde pública e das ciências sociais (cf. Ouellet-Dubé, 1979). Ora, essa distinção possui sérias repercussões para a definição do domínio de responsabilidade do pesquisador com relação aos participantes. Ela significa que o pesquisador que conduz pesquisas com seres humanos é responsável pelos atos que pratica enquanto pesquisador e por suas consequências diretas e indiretas, mas ele não é diretamente responsável por todo o contexto (social, político etc.) no qual sua pesquisa está inscrita. Os princípios éticos valem, por assim dizer, sob uma cláusula ceteris paribus: são os atos praticados em nome da pesquisa que contam de um ponto de vista ético e não as condições contextuais independentes do ato de pesquisa.

Essa distinção levanta uma dificuldade para as PPG, pois, ao integrar estreitamente a pesquisa e a ação, a produção de conhecimento e a intervenção, elas apagam essa distinção prévia posta na abordagem principialista enunciada pelo relatório 


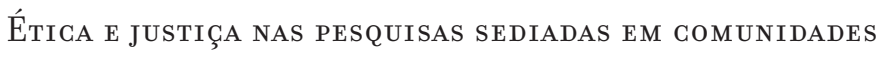

Belmont. Como se define a esfera de responsabilidade dos pesquisadores quando a pesquisa é deliberadamente contextualizada, sediada na comunidade, aberta à participação? Pelo que precisamente são responsáveis eticamente os pesquisadores das PPG? Essas questões orientarão o estudo de caso a seguir.

\section{O GASO DE UMA PESQUISA EGOSSISTÊMIGA SOBRE A POLUIÇÃO DE MERGÚRIO NA AMAZÔNIA}

No início dos anos 2000, Jean Lebel teorizou sobre a abordagem ecossistêmica na pesquisa sobre as interações entre a saúde humana e o ambiente (cf. Lebel, 2003). Essa abordagem pode ser resumida como segue. A noção de ecossistema, aplicada ao domínio da saúde pública, conduz a um alargamento dos conceitos de saúde e de doença. A saúde não é a ausência de doenças mas antes "participação harmoniosa nos recursos do ambiente, que dispõe os indivíduos a um pleno exercício de suas funções e aptidões" (Dansereau, 2003, p. viii). A abordagem ecossistêmica é antropocêntrica (são as necessidades humanas que são tomadas como referência para pensar o ecossistema), mas os problemas de saúde são contextualizados (leva-se em conta as múltiplas interações entre os humanos e seu meio). Um dos exemplos típicos desse gênero de abordagem - que serviu também como a maior fonte de inspiração para Lebel que elaborou sua tese nesse quadro - é o projeto Caruso. Essa pesquisa, da qual detalharei um episódio, foi conduzida entre 1994 e 2008 por pesquisadores canadenses e brasileiros com os habitantes das margens do rio Tapajós, no estado do Pará, na Amazônia brasileira. ${ }^{2}$

Já há muitos decênios, sabe-se que os habitantes dessas regiões estão contaminados pelo mercúrio em doses relativamente fracas via o consumo de peixes. Essa contaminação tem consequências sobre a saúde dessas populações, aumentando o risco de problemas neurológicos, funcionais e cardiovasculares (Passos \& Mergler, 2005; Lucotte et al., 2005). No início dos anos 1990, um médico cardiologista de Santarém, Fernando Branches, fazia de tempos em tempos sessões de consulta em Brasília Legal, uma vila às margens do Tapajós. A partir de certas observações clínicas inquietantes, ele levantou a questão do papel do mercúrio no estado de saúde da população e estabeleceu contatos com os pesquisadores canadenses a fim de conduzir pesquisas a esse propósito. ${ }^{3}$ Vê-se assim que a "encomenda da pesquisa” origina-se de uma personali-

2 Os detalhes sobre o projeto Caruso, financiado pelo Centre de Recherche sur le Développement International, podem ser encontradas no seguinte endereço: www.unites.uqam.ca/gmf/caruso/caruso.htm.

3 Fernando Branches é um dos que alertou a comunidade mundial sobre as relações entre o mercúrio e as alterações cardiovasculares. Ele é também o autor de um teste (o BAMT, Branches Alternate Movement Task), um teste de coordenação motora que está bem correlacionado ao nível de mercúrio. Sobre Branches, ver Lebel, 2002. 
dade local (Fernando Branches) em ligação com pesquisadores que viram nisso um terreno de pesquisa interessante. Com efeito, contrariamente a outros lugares do mundo em que as poluições pelo mercúrio são estudadas (principalmente em Minamata no Japão), parece ser nessa região amazônica o único metal presente no ambiente a afetar a saúde humana, o que torna o terreno particularmente fecundo para aqueles pesquisadores que desejam compreender o impacto próprio ao mercúrio.

No meio dos anos 1990, os pesquisadores do projeto Caruso descobriram que a presença desse metal pesado no ambiente não se devia unicamente à atividade de extração de ouro - as minas foram numerosas nas margens do rio há alguns decênios mas também às atividades agrícolas baseadas nas queimadas. $\mathrm{O}$ mercúrio presente naturalmente no solo em estado inorgânico é espalhado na água do rio pela erosão causada pelo desflorestamento, depois é transformado em uma substância orgânica assimilável pelos peixes, e pelos humanos que os consomem (cf. Roulet et al., 1999). Para descobrir a origem da contaminação pelo mercúrio, o pesquisadores tiveram a necessidade da colaboração de múltiplas disciplinas entre as ciências da terra, a biologia e as ciências sociais, o que permitiu levar em conta as múltiplas dimensões do problema. Os pesquisadores reconstituíram pouco a pouco uma rede de interações um ecossistema -, incluindo o ciclo bioquímico de transformação do mercúrio, as práticas agrícolas baseadas nas queimadas, a preferência de pesca de certas espécies, as vagas de colonização dessas terras por camponeses vindos de outras regiões do país etc. A poluição pelo mercúrio e os riscos para a saúde foram, assim, substituídos por uma análise sistêmica, situada, contextualizada, atenta ao modo pelo qual os indivíduos interagem entre si em torno desse problema.

O projeto centrou-se inicialmente sobre a avaliação da contaminação e das interações entre a poluição e as atividades humanas (abordagem descritiva e explicativa), os habitantes se propuseram a trabalhar sobre as medidas que permitissem reduzir os efeitos dessa poluição. Em uma segunda fase, a pesquisa orientou-se progressivamente para o estudo das medidas preventivas. Com base na sugestão e com a ajuda operacional de um grupo de mulheres que mantiveram um registro paciente e cuidadoso de seus menus, os pesquisadores estabeleceram por meio de estudos epidemiológicos participativos que o consumo de frutas tropicais podia ter consequências favoráveis e reduzir o nível de contaminação pelo mercúrio (cf. Passos, 2009). Durante e ao término dessas pesquisas, os habitantes receberam informações claras e acessíveis concernentes às causas da contaminação pelo mercúrio (principalmente sobre o papel da prática das queimadas) e recomendações alimentares realistas, permitindo reduzir os efeitos de longo prazo do mercúrio sobre a saúde.

Além das reuniões de informação, foram utilizados diferentes expedientes para favorecer a participação das comunidades. Uma socióloga da região constituiu grupos 
focais para avaliar qualitativamente essas medidas preventivas e, principalmente, as mudanças relativas aos hábitos alimentares, completando desse modo os dados epidemiológicos quantitativos (cf. Gaspar, 2003). Instrumentos de modelização das redes sociais permitiram igualmente descrever os circuitos pelos quais os habitantes das comunidades ribeirinhas do Tapajós podiam ser eficaz e equitativamente associados a esses conhecimentos sobre a poluição pelo mercúrio. Esses diferentes instrumentos ajudaram a identificar os líderes de opinião e o papel essencial das mulheres para o que concerne às questões de educação, alimentação e saúde.

Como se vê, o projeto Caruso foi estabelecido, passo a passo, por iniciativa dos pesquisadores, com uma preocupação de manter boas relações com as comunidades. As comunidades ribeirinhas, apesar de cansadas dos diferentes projetos (governamentais, acadêmicos ou humanitários) conduzidos até então em sua região, mantiveram com os pesquisadores relações bastante ricas, principalmente por meio das múltiplas reuniões de informação e de consulta. Pouco a pouco, a participação das comunidades no projeto Caruso passou do modo "consultivo" a um modo mais "colaborativo" (cf. Mertens et al., 2005).

\subsection{O PROJETO "VISÃo" E A PRESGRIÇão de ÓcULOS}

Uma das ações de pesquisa realizada pelos pesquisadores da equipe de saúde do projeto Caruso, o projeto "Visão", merece uma análise mais detalhada. A escolha desse caso não significa que ele deve ser considerado como o episódio mais "grave" ou "crítico" na história, bastante longa, das relações entre os pesquisadores e os participantes no Tapajós. Essa escolha decorre de um acontecimento vivido em campo que me conduziu a reconstituir-essencialmente com base nos testemunhos dos próprios pesquisadores - um episódio revelador das ambivalências da relação pesquisadores-participantes. ${ }^{4}$

O contexto científico desse subprojeto era o seguinte. As recomendações alimentares ("alimentar-se mais de peixes que não se alimentam de outros peixes") traduziam-se em uma baixa sensível da contaminação por mercúrio na localidade de

\footnotetext{
$4 \mathrm{O}$ caso relatado aqui foi reconstituído com base em testemunhos recolhidos no mês de maio de 2009, por ocasião de uma estadia de pesquisa consagrada ao projeto que substituiu o projeto Caruso, o projeto Uso da Terra pelos Pobres, Saúde dos Pobres (Poor Land Use, Poor Health), que trata das interações entre a poluição pelo mercúrio, a agricultura baseada em queimadas e a doença de Chagas e compreende uma janela de experimentação com os habitantes de sistemas agroflorestais. Aconteceu que, por ocasião de uma das visitas dos pesquisadores aos habitantes da região, estes últimos pediram insistentemente que o projeto incluísse uma disponibilização de óculos. Os pesquisadores tiveram muita dificuldade em explicar que isso não estava incluído no projeto. A partir desse evento, recolhi testemunhos sobre seu contexto junto aos pesquisadores, tanto da equipe de saúde, diretamente implicada, quanto da equipe de ambiente, assim como também dos participantes encontrados no lugar e outros testemunhos (agentes comunitários de saúde, pescadores, tripulantes do barco alugado pela equipe de pesquisa etc.).
} 
Brasília Legal, medida desde o início dos anos 2000. Entretanto, havia sido igualmente observado que as funções visuais (visão das cores e a sensibilidade aos contrastes) continuavam a baixar em função da exposição anterior. Os pesquisadores procuraram medir mais precisamente essas alterações das funções visuais. Em outubro de 2001, organizaram um teste oftalmológico junto a 98 habitantes de Brasília Legal já incluídos na pesquisa. Oftalmologistas da Universidade de Montreal instalaram um centro de atendimento temporário para efetuar essas medidas. Era preciso distinguir entre as pessoas que possuíam um mal resultado nos testes oftalmológicos em virtude da contaminação pelo mercúrio e aqueles que tinham mal resultado em função de outras patologias ou traumas oculares. Um oculista estava, portanto, presente para fornecer óculos para as pessoas que apresentavam um defeito visual não ligado ao mercúrio, a fim de que os resultados dos testes não pudessem ser contestados.

No dispositivo, havia sido previsto o fornecimento de óculos para as pessoas examinadas que tivessem necessidade deles. As lentes já estavam montadas e reguladas para os níveis de correção mais correntes. Todos os equipamentos ópticos provinham de doações de empresas canadenses. Havia também óculos de sol que - sem que isso tivesse sido na aparência coletivamente decidido - eram dados a "todas as pessoas examinadas, com ou sem prescrição" (Piéraut, 2004). Rapidamente, na própria localidade e nas comunidades em torno de Brasília Legal, correu a notícia que "a equipe do projeto mercúrio" tinha organizado um diagnóstico de problemas da visão, prescrevia gratuitamente óculos aos que precisassem deles, e oferecia a todos óculos escuros de sol. Numerosas pessoas afluíram, então, desde as outras vilas da região (frequentemente distantes de várias horas em canoa). Os pesquisadores e oculistas viram-se rapidamente envolvidos em grande confusão, pois não haviam previsto um número suficiente de óculos para equipar todos os que compareciam.

Sobretudo, diante do afluxo de pessoas que se apresentavam no centro de exame, foi necessário fazer escolhas. Os participantes do projeto Caruso tinham prioridade para a realização do exame, pois eram acompanhados nos quadros do projeto, mas sua situação oftalmológica podia ser menos urgente que a de outras pessoas, vindas eventualmente de comunidades que não participavam do projeto. Alguns habitantes tinham recebido óculos cujas correções predefinidas não eram finalmente convenientes. 5 Os óculos de sol acabaram por criar discórdia entre as crianças em época escolar e entre os adultos. Foi preciso organizar reuniões públicas nas quais os pesquisadores, os líderes locais e os habitantes constataram que não era possível satisfazer a todos. O teste foi considerado finalizado, mas o episódio mergulhou os pesquisadores e as comunidades em um certo desarranjo.

5 Testemunhas, pesquisadores e habitantes lembram-se que pessoas trocavam entre si os óculos cuja prescrição era diferente; e durante a noite, alguém se introduziu sub-repticiamente no laboratório para... mudar de óculos. 
Ética e JUSTiça NAS PESQUisas SEdiAdAs Em GOMUnidAdes

Em 2006, a fim de estudar mais precisamente os fatores em operação nas dificuldades de visão, os pesquisadores empreenderam um novo exame oftalmológico. O número de pessoas incluídas na pesquisa (448) foi então bem mais importante que da primeira vez, mas uma boa parte entre elas já havia colaborado na enquete sobre as relações entre alimentação e nível de mercúrio. O exame concernia doze comunidades (e não somente uma) e desenvolveu-se durante um período de dois anos e meio. Dois barcos especialmente contratados transportavam as pessoas entre Itaituba e suas habitações, situadas rio abaixo e acima. A fim de evitar que acontecesse a mesma confusão que da primeira vez, organizaram-se de antemão reuniões públicas de informação. Os habitantes foram informados que os participantes do projeto de pesquisa seriam submetidos a um exame oftalmológico e obteriam uma prescrição de óculos, se o exame revelasse sua necessidade. Novamente, participaram do exame oculistas canadenses, assim como dois assistentes de pesquisa locais. Agora, para aqueles cujo exame mostrava a necessidade de óculos, o projeto se responsabilizava pela armação e pelas lentes, mas desta vez foi o oculista de Itaituba que os montou. ${ }^{6}$

Essas precauções não foram, entretanto, suficientes para evitar todas as dificuldades. Mesmo se logisticamente a operação desenrolou-se bem melhor do que em 2001, as relações entre os pesquisadores e os participantes foram novamente problematizadas. Para participar no exame, algumas pessoas deviam fazer os trajetos de ida e volta de noite e ausentar-se de sua moradia por mais de 36 horas. Certos habitantes, em razão de seu trabalho (agrícola ou outro), não puderam liberar-se para participar desse exame, ainda que tivessem necessidade dele. E na escala regional, os habitantes de comunidades vizinhas que não participavam do projeto acharam injusto não ter a possibilidade de beneficiarem-se, também eles, desse exame útil. A operação parece ter gerado, ainda desta vez, certa frustração entre a população ribeirinha.

Ao final, esses dois testes oftalmológicos permitiram gerar conhecimentos pertinentes concernentes aos efeitos do mercúrio sobre a visão, mas parecem ter constituído um dos fatores perturbadores da relação entre pesquisadores e participantes (incompreensões, tentativas sem resultado, ambiguidades etc.). Em 2009, ainda acontecia que os habitantes da região do Tapajós associavam a equipe do "projeto mercúrio" com a possibilidade de obter óculos. Quando os pesquisadores do projeto visitam as comunidades sem mencionar o problema particular dos problemas de visão, os habitantes pedem informações sobre o fornecimento dos óculos, insistindo sobre a importância que isso representa para eles. Os pesquisadores são obrigados a responder, não sem certo embaraço, não poder fazer isso ou mesmo não querer fazê-lo.

6 No relato que redigiu ao seu retorno, o oculista estimou que uma solução melhor teria sido agir “não como 'gringos', mas como missionários", isto é, transmitindo seu saber fazer de oculista (montagem, regulagem etc.) a uma pessoa do lugar. A escolha, em 2006, foi a de apoiar-se sobre os recursos locais. 


\subsection{Deveres dos Pesquisadores e ASSistênGia À comunidade}

Que lição podemos retirar desses dois episódios? Não houve certamente um grave problema ético, mas resultou uma dificuldade difusa, que exige várias considerações. Inicialmente, é preciso lembrar que nenhuma pesquisa em contato com a população é absolutamente anódina, sem consequências na vida das pessoas. Toda pesquisa de campo acarreta para os pesquisadores, assim como para os participantes, experiências singulares que não são humanamente neutras. Além disso, essas oportunidades não são necessariamente repartidas equitativamente. Como o financiamento dos pesquisadores é necessariamente limitado, o número de participantes também o é, e a pesquisa não concerne então senão a um subgrupo de uma população que pode, ademais, ter sido escolhida ao acaso, por razões contingentes, "meramente" práticas. Nesse caso, em 2001 foi em Brasília Legal que o teste foi realizado, pois foi nessa localidade, desservida por transportes fluviais regulares, que a equipe de pesquisa inicialmente ficou sediada.

$O$ fato de que a pesquisa é acompanhada pela produção de um bem ou de um serviço (no caso, responsabilizar-se por uma correção óptica) reforça a desigualdade entre os incluídos e os não incluídos. No caso, essa ação de diagnóstico e de assistência é feita em uma região em que as pessoas que têm problema de vista não possuem, na maior parte do tempo, os recursos necessários para ir a Itaituba ou a Santarém e obter óculos de correção. De modo geral, os habitantes das margens do Tapajós vivem bastante longe e não possuem senão um acesso bastante limitado aos serviços básicos de saúde. Em Brasília Legal, por exemplo, há apenas um posto de saúde, no qual trabalha apenas um único agente comunitário de saúde, que deve visitar todas as vilas da região sem equipamento específico, nem, evidentemente, serviço de oftalmologia.

A questão é, portanto, a seguinte: para um equipe de pesquisa estrangeira, presente periodicamente na região e que não intervém senão em uma parte da população regional, deve-se ver essa situação de carência generalizada como uma razão para não oferecer a assistência ou, ao contrário, como uma razão para propor uma assistência, mesmo que limitada em seu alcance e em sua duração?

Pode-se considerar que isso vale para a assistência, assim como para o dever de informar os resultados dos testes. De modo geral, no quadro do projeto Caruso, os resultados dos testes eram informados sob a forma individual a cada participante e sob a forma de resultados gerais nas reuniões públicas. Em princípio, os participantes sabiam o que os pesquisadores sabiam a seu respeito. Além disso, o diagnóstico da visão em si mesmo não levantava problema ético particular, o que contrasta com os casos correntemente discutidos na literatura (por exemplo, Tortevoye et al., 2007). Mas se o diagnóstico revela no participante um problema de vista, e se existem os meios, não 
disponíveis localmente, para corrigi-lo, mesmo imperfeitamente, é um dever dos pesquisadores de pôr em operação esses meios?

Os textos de referência do CIOMS para a pesquisa biomédica evocam o dever, quando as pesquisas concernentes populações de recursos limitados, de assegurar um "acesso razoável" aos produtos ou dispositivos testados. ${ }^{7}$ No projeto relativo à visão do Caruso, não se tratava de testar um método terapêutico, mas era antes uma pesquisa que visava compreender os efeitos do mercúrio e acompanhar os habitantes na identificação de soluções robustas para esses efeitos. O princípio de um "acesso razoável" concerne, portanto, aos resultados da pesquisa, a saber, aos conhecimentos produzidos relativos ao sistema humano/ambiente/mercúrio. Os pesquisadores consideraram, entretanto, que pertencia a sua responsabilidade ir além, e assegurar, para as pessoas que tinham um problema de visão diagnosticado no curso da pesquisa, um acesso aos serviços oftalmológicos. Ao posicionarem-se, por meio de um ato de triagem, do ponto de vista da responsabilidade clínica, individual - a ética do cuidado -, eles estimaram que pertencia a seu dever disponibilizar óculos para aqueles a quem isso ajudaria.

Se nos colocamos agora do ponto de vista da ética da saúde pública e do bemestar coletivo, o argumento é diferente. Por exemplo, uma medida útil no plano individual, mas que se revela coletivamente injusta, pois não é igualitária, é coletivamente mais útil que a decisão de se abster? A resposta a essa questão depende do "valor" atribuído à injustiça, bem como da comparação entre as duas faces da ação realizada. De um lado, ao fornecer óculos aos participantes, os pesquisadores provavelmente aportaram um benefício claro, direto, em resposta a necessidades identificadas; de outro lado, essa intervenção, ao não tocar o principal problema (a oferta de cuidados de saúde na escala regional), pode também ter o efeito perverso comum às ações assistenciais, a saber, substituir temporariamente a oferta pública de cuidados, sem que isso conduza à melhoria dessa última. Por falta de dados factuais, não discutirei mais aqui essa questão.

Falta tratar de outra dimensão subjacente a esse caso, a da compensação aos participantes da pesquisa. No que concerne à intenção da equipe de pesquisadores, existem duas versões. A primeira é dada, por exemplo, pelo oculista que participou da pesquisa em 2001, que qualifica de modo ambivalente a participação dos habitantes. Por

7 Adiretiva n. 10 das "linhas diretrizes internacionais de ética para a pesquisa biomédica implicando sujeitos humanos”, editadas pelo Conselho das Organizações Internacionais das Ciências Médicas (CIOMS), com a colaboração da Organização Mundial da Saúde (OMS), Genebra, 20o3, estipula que toda intervenção ou produto elaborado ou todo conhecimento obtido será razoavelmente posto à disposição para o benefício dessa população ou comunidade. Essa diretiva seguiu-se ao debate a propósito da revisão do parágrafo 3. da declaração de Helsinki (Assembleia Médica Mundial) em 2000. A noção de "disponibilidade razoável”, bastante vaga, deixa a porta aberta para a negociação para saber quem, os pesquisadores ou o poder público, deve assegurar essa disponibilização dos tratamentos que se originaram da pesquisa, por quanto tempo, e quem pode ter, e terá, o direito (os participantes unicamente ou o conjunto da comunidade). 
um lado, a disponibilização de óculos é apresentada como fazendo parte integrante do protocolo de pesquisa, enquanto instrumento capaz para identificar as dificuldades de visão atribuíveis ao mercúrio nessa população. A partir daí, segue-se a imagem de pesquisadores que, animados por uma intenção louvável, põem em prática um teste com suas restrições e vantagens junto a populações também elas prontas a cooperar. "Ao vir para estudar o problema, diz nosso oculista, acabamos por criar bastante confusão em seu cotidiano. E, ainda assim, talvez por curiosidade, elas se mostraram sempre bastante cooperativas". De outro lado, os óculos são apresentados como um instrumento de fidelização, como um mecanismo de compensação, que permite "manter a população interessada em passar pela bateria de testes (...). Como os testes visuais vinham por último, os óculos ofertados eram de certo modo uma recompensa, um presente pela participação, como nas feiras beneficentes" (Piéraut, 2004, p. 5). Essas recompensas dadas aos participantes são, assim, apresentadas simplesmente como "aceitáveis", $\mathbf{8}$ mas esse relato parece desencantar a relação entre os pesquisadores e os participantes, frequentemente valorizada na pesquisa participativa.

De fato, os pesquisadores interrogados divergem vivamente dessa interpretação e propõem uma segunda: em sua intenção, os óculos não eram absolutamente uma compensação ou um presente, mas antes um gesto sanitário que era eticamente exigido. Para eles, prescrever e pôr à disposição óculos a quem tinha necessidade é articular convenientemente os deveres e os interesses de cada um. De um lado, certamente os participantes "doam um pouco de si" (cf. Fagot-Largeault, 1991), gastam um tempo para passar pelo teste e para contribuir na avaliação da relação entre o mercúrio e os problemas de vista; de outro lado, eles podem "beneficiar-se" não apenas de um retorno de informação sob a forma de resultados optométricos e de conhecimentos mais gerais, mas também, caso haja necessidade, de um acesso imediato a óculos para corrigir as dificuldades constatadas. Desse ponto de vista, poder-se-ia estabelecer a relação de reciprocidade entre esses dois "dons". Os interesses de cada um - os pesquisadores que querem obter os dados e os habitantes que querem beneficiar-se da assistêncianão estão separados, mas são mutuamente partilhados.

De modo geral, no projeto Caruso, foi feita a escolha de evitar tanto quanto possível que a participação das pessoas fosse feita em troca de contrapartidas em natura ou em dinheiro. Se a pesquisa tem, para os participantes, custos diretos (combustível,

8 O comentário da recomendação n. 7 das "linhas diretrizes éticas internacionais para a pesquisa epidemiológica" da CIOMS (2009) estabelece, com efeito, uma distinção entre as recompensas "aceitáveis" e as recompensas "inaceitáveis". Dentre as primeiras figuram o reembolso de transporte, uma soma modesta de dinheiro para contrabalançar necessidades não compensadas de outro modo, prestações médicas (que tenham ou não relação com a pesquisa) e o acesso gratuito aos procedimentos, testes e exames. As recompensas inaceitáveis são aquelas que, dado o seu montante, sua natureza ou o contexto, falsificam o juízo do participante. Evidentemente, o limite entre as duas categorias é móvel, mas a ideia geral é que as compensações podem ser legítimas. 
Ética e Justiça NAS PESQuisas SEdiadas em Gomunidades

alimentos etc.), esses custos são assumidos pelos pesquisadores, os quais possuem um financiamento para isso. Ao contrário, os tempos de reunião, de conversação, o tempo gasto para responder a questionários ou a consultas não são remunerados. Além disso, poder-se-ia considerar que, a princípio, essa posição não é evidente. Por que os pesquisadores recebem um salário enquanto os participantes não o recebem? A mulher participante que coordenou a coleta de dados de alimentação junto às mulheres de sua vila foi remunerada, a título de copesquisadora ou colaboradora. Mas pode ser que se a prática tivesse sido generalizada para todos, o pagamento do tempo gasto no projeto e o estabelecimento de relações salariais trariam o risco de gerar perturbações sobre a economia local e, sobretudo, de transformar a relação pesquisadores/comunidades em uma relação empregador/empregado, com o risco de produzir principalmente efeitos de dependência.

Os testemunhos recolhidos indicam que os pesquisadores do projeto Caruso, provavelmente felizes com as relações que se estabeleceram ano após ano com os habitantes, e desejosos de ser-lhes diretamente benéficos, traziam frequentemente consigo coisas julgadas úteis à comunidade (medicamentos listados pela enfermaria da vila, cadernos para a escola etc.). Essas coisas permitiam aos pesquisadores fazer "um presente coletivo" às comunidades que os acolhiam, sem que por isso se entrasse em um sistema de compra da participação de cada um. Quanto aos óculos, porque eles constituíam ao mesmo tempo um bem raro e, além disso, não disponível, porque beneficiavam a alguns e não a todos, e porque sua disponibilização estava centrada no indivíduo e não no coletivo, parecem ter abalado a abordagem coletiva e comunitária.

\section{As EXIGÊNGIAS DISTINTAS DA PESQUisa E DA AÇÃO}

Para concluir, desenvolverei dois comentários de modo a pôr em perspectiva esse caso. O primeiro lembra a exigência - que permanece muito ambiciosa - de participação das comunidades na abordagem ecossistêmica. Qual é o balanço que as populações ribeirinhas do Tapajós fazem desse dispositivo? Até onde elas foram uma parte participante na montagem assegurada pelos pesquisadores para realizar os diagnósticos de acuidade visual? Deve-se notar que nem em 2001, nem em 2006 os habitantes estiveram associados à decisão de propor uma assistência a partir da triagem e suas modalidades, o que explica provavelmente que os pesquisadores, acreditando estarem fazendo um bem, não levaram em conta todas as consequências dessa medida. De outro ponto de vista, o afluxo de pessoas de toda a região e o transbordamento do dispositivo concebido pelos pesquisadores (principalmente na primeira ocorrência do "Projeto visão" em 2001) não é talvez o signo de um mal-entendido na comunicação, mas uma maneira pela qual 
a realidade se impôs aos pesquisadores. Pode-se considerar o episódio optométrico e o reboliço que ele causou, não simplesmente como uma perturbação da relação entre os pesquisadores e os participantes, mas mais positivamente como a ocasião pela qual os habitantes puderam intervir sobre a intervenção dos pesquisadores.

Ao reclamar os óculos, as populações ribeirinhas "participaram” no projeto dos pesquisadores indicando o que nele, para essas populações, constituía uma questão de mobilização possível. Retornava, então, para os pesquisadores, em função de suas possibilidades e de seus próprios interesses, a decisão de seguir ou não essa sugestão. Nessa ocorrência, o projeto de pesquisa não estava centrado sobre a questão do acesso à saúde na região, mas na questão da contaminação pelo mercúrio e das medidas de prevenção primária. A abordagem global ambicionada pelos pesquisadores tornou provavelmente mais difícil a demarcação entre o que constituía ou não seu campo de intervenção. A “proposição" dos habitantes ficou, por assim dizer, sem resposta adequada, mesmo que tenha sido a ação dos pesquisadores que de algum modo a suscitou.

O segundo comentário remete, desse modo, à questão do papel dos pesquisadores e à definição de sua esfera de responsabilidade. A introdução do relatório Belmont, citada mais acima, indica em substância que a ética da pesquisa e a ética da prática são duas esferas que não se recobrem completamente. Proponho para isso a seguinte interpretação: os pesquisadores possuem responsabilidades específicas enquanto pesquisadores, porque a pesquisa é, de algum modo, um "luxo". Produzir conhecimentos novos jamais é uma obrigação prima facie, mas uma escolha que se faz em função de fins e de interesses determinados. 9 Procurar gerar conhecimentos é um suplemento, desejável, útil (se quisermos), mas jamais uma obrigação em si. É por isso que exigências éticas particulares foram postas em funcionamento, específicas para as pesquisas conduzidas com seres humanos (principalmente os princípios de respeito, de beneficência e de justiça). Trata-se de garantir que a pesquisa, que nunca é absolutamente necessária, não será conduzida lesando indivíduos e grupos. Por contraste com a pesquisa, concebida como uma atividade que também poderia não existir, a ação - seja ela médica, humanitária, individual etc. - está envolvida com as exigências que nascem das condições de existência. Intervir no e sobre o mundo não depende de uma escolha, é uma condição ligada à vida humana. Não se trata de dizer que não existem ações supérfluas, nem que as ações não deveriam ser submetidas à avaliação ética. A ética da prática supõe evidentemente interrogar a boa fundamentação das intenções, levar em conta as diferentes consequências e considerar as diferentes opções possíveis, inclusive

9 Todo programa de pesquisa increve-se em um "esquema de significação", um conjunto de interesses e de fins que não se impõem por si mesmos e requerem explicitação e discussão. Essa é claramente a advertência de Kitcher (2001). 
aquela de não agir. Assim, manter simplesmente no espírito a distinção entre a pesquisa e a ação permite evitar a confusão entre dois registros de justificação diferentes.

Como vimos ao início deste artigo, as PPC possuem como particularidade a de mover-se simultaneamente nessas duas esferas, a da pesquisa e a da ação. Essa ambivalência gera ambiguidades com as quais se confrontam tanto os pesquisadores, quanto as comunidades. Essas ambiguidades geram-se entre aquilo que é da ordem do possível (a pesquisa) e o que é da ordem do inevitável (a ação). As PPC não são simplesmente nem pesquisa que se mantém a uma boa distância de seu objeto, nem simplesmente ação, prisioneiras do contexto no qual se engajam. A oscilação entre a pesquisa e a ação, entre a distância e a participação, não parece virtuosa senão na medida em que vem acompanhada de um aumento na vigilância e na lucidez.

Traduzido do original em francês por Pablo Rubén Mariconda.

\author{
Nicolas LeGHopie R \\ Maître de Conference, \\ Université de Lyonı, França. \\ nicolas.lechopier@univ-lyonı.fr
}

\begin{abstract}
Since the 1970s, community-based participatory research methods have gradually gained credit in the field of applied research, leading to epistemic and ethical mutations in research practices with human participants. This article draws on an example of a ecosystemic community-based research, conducted in partnership between academic researchers (Canada and Brazil) and inhabitants of the banks of a river in the Brazilian Amazon, the Tapajós. This example illustrates the tensions that affect the conceptual framework in which ethical issues of research involving human participants are usually raised, particularly the cardinal principles of beneficence and justice drawn from the Belmont Report. This kind of scientific practice involves a redeployment of the researchers responsibilities, between research and action.
\end{abstract}

KeYwords $\bullet$ Research ethics. Ecosystemic approach. Participatory research. Ethical dilema.

Environmental health. Global health. Amazon.

\title{
REFER ÊNCIAS BIBLIOGRÁFIGAS
}

Adelman, C. Kurt Lewin and the origins of action research. Educational Action Research, 1, 1, p. 7-24, 1993. American National Commission. The Belmont report: ethical principles and guidelines for research involving human subjects. Washington DC: US Govt Printing Office (DHEW), 1984 [1978].

Beguin, P. \& Cerr, M. (Ed.). Dynamique des savoirs, dynamique des changements. Toulouse: Octares, 2009. 
ChamaYou, G. Les corps vils. Expérimenter sur les êtres humains aux XVIIIè et XIXè siècles. Paris: La Découverte/Les empêcheurs de penser en rond, 2008.

FAGot-Largeault, A. Autonomie, don et partage dans la problématique de l'expérimentation humaine. Dialogue, 3o, p. 355-63, 1991.

Freire, P. Pedagogia do oprimido. Rio de Janeiro: Paz e Terra, 1978.

GASPAR, E. Contamination mercurielle en Amazonie: recherche participative avec des femmes riveraines pour réduire l'exposition au mercure. Montréal, 2003. Tese (Doutorado em Ciências do Ambiente). Université du Québec à Montréal, Canada.

Green, L. D. M. \& Novick, M. Partnerships and coalitions for community-based research. Public Health Reports, 116, p. 20-31, 2001.

Israel, B. et al. Health education and community empowerment: conceptualizing and measuring perceptions of individual, organizational and community control. Health Education Quarterly, 21, 2, p. 149-70, 1994 .

Review of community-based research: assessing partnership approaches to improve public health. Annual Review Public Health, 19, p. 173-202, 1998.

King, N. et Al. Relationships in research: a new paradigm. In: King, N., Henderson, G. \& Stein, J. (Ed.). Beyond regulations: ethics in human subjects research. Chapel Hill: University of North Carolina Press, 1999. p. 1-18.

King, N.; Henderson, G. \& Stein, J. (Ed.). Beyond regulations: ethics in human subjects research. Chapel Hill: University of North Carolina Press, 1999.

Kitcher, P. Science, truth and democracy. New York: Oxford University Press, 2001.

Lagey, H. Valores e atividade científica 1. São Paulo: 34/Associação Filosófica Scientiæ Studia/Parque CienTec, 2008.

Lebel, J. Hommage à un chercheur brésilien, Fernando Branches. Centre de Recherches pourle Développement International, 2002. Disponível em: 〈http://www.idrc.ca/fr/ev-294.05-201-1-DO_TOPIC.html〉. Acesso em: 25/03/2011.

. La santé: une approche écosystémique. Ottawa: Centre de Recherches pour le Développement International, 2003.

Lewin, K. Action research and minority problems. Journal of Social Issues, 2, 4, p. 34-4,6, 1946.

Lucoтte, M. et al. Human exposure to mercury as a consequence of landscape management and socioeconomical behaviors. Part I: the Brazilian Amazon case study. RMZ-Materials and Geoenvironment, $5^{1}$, p. $668-72,2005$.

MAcKLIN, R. Against relativism: cultural diversity and the search for ethical universals in medicine. New York: Oxford University Press, 1999.

Massé, R. Valeurs universelles et relativisme culturel en recherche internationale: les contributions d'un principisme sensible aux contextes socioculturels. Autrepart. Revue de l'Institut de Recherche pour le Développement, 28, p. 21-35, 2003.

Mertens, F. et al. A network approach for analysing and promoting equity in participatory ecohealth research. EcoHealth, 2, 2, p. 113-26, 2005.

MiNKLER, M. Ethical challenges for the "outside" researcher in community-based participatory research. Health Education \& Behavior, 31, 6, p. 684,-701, 2004.

MinkLer, M. et al. Community-based participatory research: implications for public health funding. American Journal of Public Health, 93, 8, p. 1210, 2003.

Mohan, G. Not so distant, not so strange: the personal and the political in participatory research. Ethics, Place and Environment, 2, 1, p. 41-54, 1999.

Müller-Mirza, N. Qu'est-ce qui ce développe dans et par une formation-action? In: Beguin, P. \& Cert, M. (Ed.). Dynamique des savoirs, dynamique des changements. Toulouse: Octares, 2009. p. 229-44. 
Ouellet-Dubé, F. Recherche ou pratique: qui gagne? Service Social, 28, 2-3, p. 5-14, 1979.

Passos, C. J. S. \& Mergler, D. Human mercury exposure and adverse health effects in the Amazon: a review. Cadernos de Saúde Pública, 24, 4, p. 503-20, 2005.

Passos, C. J. S. Alimentation locale et exposition au mercure en Amazonie brésilienne. Bulletin d'Information en Santé Environnementale, 20, p. 10-4, 2009.

Piéraut, J.-P. Un opticien à Brasília Legal. Forum Amazonien sur la Contamination des Écosystèmes par le Mercure, 2001. Disponível em: <http://www.facome.uqam.ca/pdf/Un_opticien_a_Brasilia_ Legal.PDF>. Acesso em: 23/01/2011.

Un opticien quebecois en Amazonie, 3è partie. Coup d'oeil, juillet-août, 2004. Disponível em: < http://www.bretoncom.com/coupdoeil/2004/o7/og.asp>. Acesso em 25/o3/2011.

Roulet, M. et al. Effects of recent human colonization on the presence of mercury in Amazonian ecosystems. Water, Air and Soil Pollution, 112, p. 297-313, 1999.

Sнове, N. Re-conceptualizing the Belmont report: a community-based participatory research perspective. Journal of Community Practice, 14, 4, p. 5-26, 2006.

Strauss, A. L. \& Corbin, J. Basics of qualitative research: techniques and procedures for developing grounded theory. Londres: SAGE, 2008.

Thiery, O. \& Cerf, M. Penser la recherche participative comme une pratique. Une proposition de diagnostic. Beguin, P. \& Cert, M. (Ed.).Dynamique des savoirs, dynamique des changements. Toulouse: Octares, 2009. p. 4.4.

Tortevoye, P. et al. Analyse des enjeux éthiques soulevés au cours d'un programme de recherche épidémiologique de dix années en Guyane française: limites de l'encadrement actuel et solutions adoptées. Revue d'Épidémiologie et de Santé Publique, 55, p. 413-21, 2007.

Turckнеiм, E. de et al. L'évaluation des recherches partenariales: quelle procédure, quels critères? In: Beguin, P. \& Cert, M. (Ed.). Dynamique des savoirs, dynamique des changements. Toulouse: Octares, 2009. p. 233-50. 